\title{
CARACTERÍSTICAS FÍSICO-QUÍMICAS, NUTRICIONAIS E FORMAS DE CONSUMO DA QUINOA (Chenopodium quinoa Willd.)
}

\section{PHYSICOCHEMICAL AND NUTRITIONAL CHARACTERISTICS AND USES OF QUINOA (Chenopodium quinoa Willd.)}

\author{
João T. Borges, Renata C. Bonomo¹, Cláudia D. Paula², Ludmilla C. Oliveira³, Márcia C. \\ Cesário ${ }^{4}$
}

Recibido para evaluación: Febrero 28 de 2010 - Aceptado para publicación: Junio 8 de 2010

\begin{abstract}
RESUMO
A quinoa (Chenopodium quinoa Willd.) é uma planta da família Chenopodiaceae, cultivada em diferentes regiões na América do Sul, especialmente nos Andes, tendo sido recentemente introduzida na Europa, América do Norte, Ásia e África. No Brasil, seu consumo é limitado devido ao alto custo do grão importado, ao desconhecimento da população e à baixa disponibilidade de cultivares adaptadas às condições locais. O presente trabalho tem por objetivo revisar os aspectos relacionados à composição química, nutricional e antinutricional de quinoa e suas principais formas de consumo. O valor nutritivo deste grão é superior ao da maioria dos cereais consumidos no Brasil. Os fatores antinutricionais presentes na semente de quinoa são saponinas (principal), ácido fítico, taninos e inibidores de tripsina. Estas substâncias encontram-se presentes em maior concentração nas camadas mais externas do grão, sendo, contudo, facilmente removidas por métodos úmidos ou secos e tratamento térmico. Comercialmente, encontram-se disponíveis os grãos, integral ou polido, e farinhas, podendo ser aplicados em diversos produtos, seja como ingrediente principal ou em combinação com outros, na preparação de diferentes derivados alimentícios (massas alimentícias, snacks, flocos, farinhas instantâneas, produtos de panificação, dentre outros).
\end{abstract}

Palavras-chave: Quinoa, composição química, fatores antinutricionais.

\begin{abstract}
Quinoa (Chenopodium quinoa Willd.) is a plant from the Chenopodiaceae family. This plant is grown in different regions of South America, specially in the Andes region, and it was recently introduced in Europe, North America, Asia and Africa. In Brazil, the quinoa plants use is limited due to the high costs of imported

'Universidade Estadual do Sudoeste da Bahia. Praça Primavera, n 40. Primavera. Itapetinga, Bahia. Brasil. Tel.: (77) 2618600. E-mail: jtsborges@yahoo.com.br.

${ }^{2}$ Universidad de Córdoba. Km 3, vía Cereté, Córdoba. E-mail: cdenise@sinu.unicordoba.edu.co.

${ }^{3}$ Universidade Federal de Viçosa. Avenida P. H. Rolfs. Viçosa, MG. Brasil. E-mail: millinha_oliveira@hotmail.com.

${ }^{4}$ Instituto Federal Minas Gerais. Avenida $1^{\circ}$ de Junho. Centro. São João Evangelista, MG. Brasil. E-mail: marcia.cesario@ ifmg.edu.br.
\end{abstract}


grains, the lack of knowledge by people and the few cultivars adapted to local conditions. This paper aims to review aspects related with quinoa chemical composition, nutrition and consumption. Quinoa grain nutritional value is higher than most cereal consumed in Brazil; however, quinoa seeds have saponins (main), phytic acid, tannins and trypsin inhibitors. These substances are present in higher concentration in external grain layers but can be easily removed by wet, dry and heat treatment. Commercially quinoa is found as whole, flour or polished grains form that can be applied to various products, either as main ingredient or combined to prepare derivative foods (pasta, snacks, flakes, flour, instant bakery products, among others).

Key words: Quinoa, chemical composition, antinutritional factors.

\section{INTRODUÇÃO}

A quinoa (Chenopodium quinoa Willd.) é uma cultura anual, pertencente à família Chenopodiaceae, a mesma do espinafre e da beterraba, cultivada desde o nível do mar até uma altitude de $3800 \mathrm{~m}$, podendo crescer em diferentes tipos de solos, com ciclo variando de 80 a 150 dias nas condições do Brasil Central. Originária da América do Sul tem sido cultivada em diferentes regiões desse continente, especialmente nos Andes e em países como Colômbia, Chile, Bolívia, Equador e Peru, sendo recentemente introduzida na Europa, América do Norte, Ásia e África (Spehar e Santos 2002; Brady et al. 2007; Nsimba et al. 2008).

O plantio da semente para fins de pesquisa no país teve inicio na década de 1990, como parte do esforço para diversificar o sistema de produção do Bioma Cerrado. Durante o processo de seleção, foram obtidos vários genótipos, originando a cultivar BRS Piabiru, sendo, portanto, a primeira recomendação para o cultivo no país, com rendimento médio de grãos de aproximadamente 2,8 $\mathrm{t} \mathrm{ha}^{-1}$ (Spehar e Santos 2002; Spehar et al. 2003; Rocha 2008), superior à média de produção registrada no
Equador e Peru nos anos de 1998 a 2000 (0,5 a $0,98 \mathrm{t} \mathrm{ha}^{-1}$ ) (Estudio de quinua 2003) e Bolívia em 2001 (0,64 t ha $\left.{ }^{-1}\right)$ (Rojas et al. 2004). A área plantada, ainda que pequena, tem potencial de crescer, para atender à demanda, hoje suprida pelo produto importado. Preços atrativos fazem aumentar o interesse de produtores, pesquisadores e indústria alimentícia.

O nome quinoa se aplica tanto à planta quanto ao grão, um fruto do tipo aquênio (Figura 1), que amadurece enquanto a planta seca, permitindo sua colheita mecanizada. Tem forma cilíndrica, achatada e tamanho variando de 2 a 2,5 mm de diâmetro e 1,2 a 1,6 mm de largura (Tapia 1997; Spehar e Santos 2002). Apresenta como principais estruturas anatômicas o pericarpo, o episperma (testa), o perisperma e o embrião (radícula e cotilédones), sendo por esta razão considerada semente, de modo semelhante ao tratamento dado aos grãos de cereais. Sua cor é resultante da combinação da coloração do pericarpo e do episperma. O pericarpo pode ser translúcido, branco, amarelo, rosa, vermelho, laranja, marrom, cinza ou preto. Frutos com cores claras no pericarpo têm perisperma branco e os frutos escuros têm episperma marrom ou preto (Koziol 1993; Prego et al. 1998). 


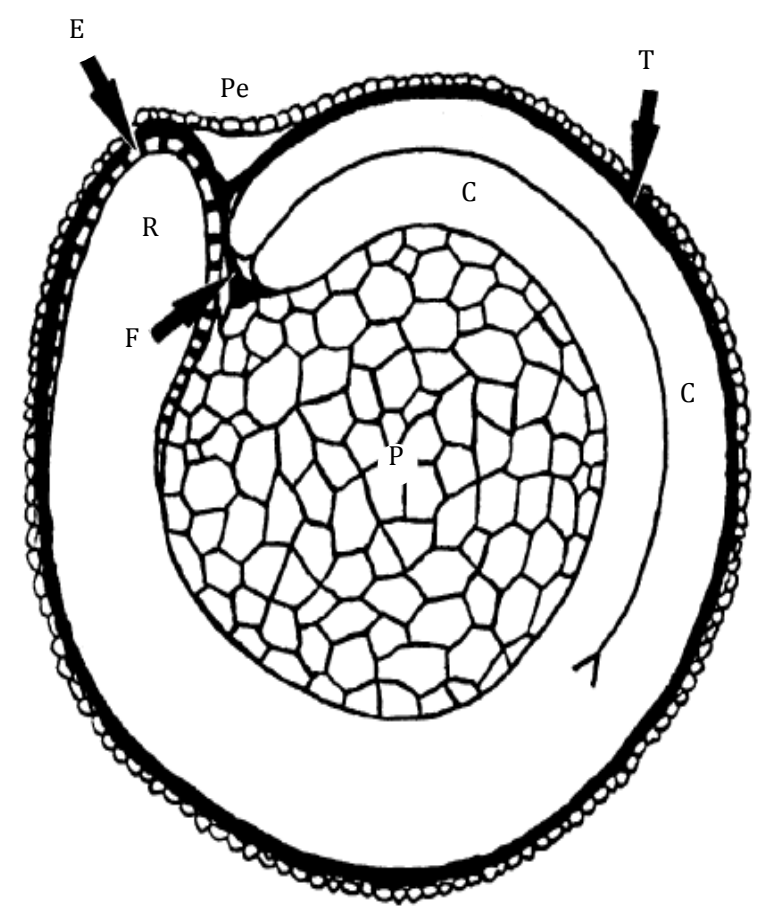

Figura 1. Representação esquemática do corte longitudinal do grão de quinoa (E: endosperma, Pe: pericarpo, P: perisperma, $\mathrm{R}$ : radícula, F: funículo, C: cotilédones, $\mathrm{T}$ : testa). Fonte: Prego et al. (1998)

A semente apresenta o perisperma como seu principal tecido de reserva nutricional, correspondente ao endosperma nos grãos de cereais. Pela proximidade em composição organo-mineral à dos cereais, sem, no entanto, pertencer à mesma família botânica, a quinoa é freqüentemente referida como um "pseudocereal" (Spehar 2002).

Por suas características nutricionais, a farinha de quinoa destaca-se como ingrediente alimentar altamente desejável para consumo como alimento de subsistência (base alimentar) ou para o enriquecimento da dieta de muitas comunidades em países subdesenvolvidos ou em desenvolvimento. O valor biológico de sua proteína faz com que seu grão seja aplicável na fortificação de farinhas de trigo, milho e tubérculos (Castro et al. 2007), enquanto a ausência de gliadinas (presentes no trigo) e frações protéicas correspondentes às gliadinas (encontradas na cevada, centeio e malte), a torna adequada na elaboração de produtos farináceos popularmente referidos como "isentos de glúten"; aspectos importantes que possibilitam uma maior variedade e oferta de produtos alimentícios mais nutritivos e adequados aos portadores da doença celíaca (Mearin et al. 2005; Rodrigo 2006; Castro et al. 2007; Almeida et al. 2008).

No Brasil, o consumo de quinoa é limitado em virtude do alto custo do grão importado, do desconhecimento da população, de hábitos e costumes tradicionais de cereais como arroz, trigo e milho e da baixa disponibilidade de cultivares adaptadas às condições locais. Ademais a planta e o grão têm sido pouco estudados e seu consumo chega a ser desconhecido pela maioria da população. Desta forma, são necessários novos estudos, de maneira a investigar cada vez mais a viabilidade tecnológica, nutricional, funcional e de cultivo desta granífera, consolidando seu uso como mais uma matéria-prima na dieta alimentar brasileira. Neste trabalho objetivase revisar aspectos relativos à composição química, nutricional e antinutricional de quinoa e suas principais formas de consumo.

\section{COMPOSIÇÃO QUÍMICA E ASPECTOS NUTRICIONAIS}

Apesar de seu consumo estar restrito a alguns países e ainda, dentro de certas regiões, o potencial da quinoa como fonte nutricional é elevado. O interesse no seu aproveitamento é reconhecido por órgãos internacionais como 
a Food and Agriculture Organization/World Health Organization (FAO/WHO) e a National Aeronautics and Space Administration (NASA) (Dini et al. 2006; Comai et al. 2007; Jancurová et al. 2009a), por exemplo, sendo necessário o desenvolvimento de produtos de qualidade sensorial adequada, como forma de viabilizar sua incorporação à alimentação humana.

A tabela 1 apresenta a composição da quinoa em comparação com os cereais arroz, milho (fubá) e trigo (farinha). Pode-se notar que a quinoa possui teores superiores de lipídeos, proteína, cinzas e fibra alimentar. Sua proteína destaca-se pelo elevado teor de lisina e outros aminoácidos essenciais, quando comparada aos cereais, o que dentre outros fatores, vem despertando a atenção de pesquisadores no mundo inteiro para o potencial nutricional desta granífera, mesmo considerando a presença de ácido fítico em suas camadas periféricas (Hunt et al. 2002; Gely e Santalla 2007).

Ogungbenle (2003) estudando características químicas de farinha de quinoa registrou teores 13,5\% de proteína, 6,3\% de lipídios, 9,5\% fibra bruta, $1,2 \%$ cinzas totais, $58,3 \%$ de carboidratos (com base de 11\% de umidade), além de altas proporções de D-xilose (120,0 mg $\left.100 \mathrm{~g}^{-1}\right)$, maltose (101,0 mg $\left.100 \mathrm{~g}^{-1}\right) \mathrm{e}$ baixos teores de glicose (19,0 mg $\left.100 \mathrm{~g}^{-1}\right)$ e frutose (19,6 mg $\left.100 \mathrm{~g}^{-1}\right)$.

O grão de quinoa apresenta excelente balanço entre lipídios, proteínas e carboidratos, sendo o pericarpo, embrião e perisperma as principais estruturas de armazenamento. O amido é armazenado no perisperma, enquanto que lipídeos e proteínas estão presentes principalmente no endosperma e embrião. O conteúdo de amido pode variar de 51 a 61\%, consistindo de grânulos de tamanho uniformes e pequenos (inferior a $3 \mu \mathrm{m}$ de diâmetro). As fibras do grão correspondem em média a 3,8\%, sendo este nível maior do que os encontrados no arroz, milho e trigo (Prego et al. 1998; Ascheri et al. 2002; Lindeboom 2005).

Ando et al. (2002) e Konish et al. (2004) analisaram o conteúdo de minerais no grão de quinoa polida (100 g de amostra), obtendo dentre os minerais analisados, maiores teores de cálcio (55,1 a 91,8 mg), fósforo (360,2 a 411,0 mg), potássio (639,3 a 732,0 mg), magnésio (415,2 a 502,0 mg), ferro (9,2 a 15,0

Tabela 1. Composição centesimal aproximada (\% base seca) de quinoa, arroz, fubá de milho e farinha de trigo

\begin{tabular}{lcccc}
\hline Composição & Quinoa $^{\mathbf{1}}$ & Arroz $^{\mathbf{2}}$ & ${\text { Fubá de } \text { milho }^{\mathbf{2}}}$ & Farinha de trigo $^{\mathbf{2}}$ \\
\hline Lipídeos & 5,77 & 0,35 & 2,15 & 1,61 \\
Proteína & 16,12 & 8,30 & 8,13 & 11,26 \\
Cinzas & 2,83 & 0,58 & 0,68 & 0,92 \\
Carboidratos totais & 75,28 & 90,77 & 89,04 & 86,21 \\
Fibra alimentar & 9,59 & 1,84 & 5,31 & 2,64 \\
\hline
\end{tabular}

Fonte: ${ }^{1}$ Wright et al. (2002), ${ }^{2}$ NEPA (2006). 
mg) e zinco (0,8 a 4,0 mg). Alguns estudos comprovam que o grão de quinoa apresenta quantidades significativamente superiores para estes minerais quando comparado à maioria dos cereais comumente consumidos no Brasil (trigo, milho, arroz, aveia) (Ascheri et al. 2002; Repo-Carrasco et al. 2003; Borges et al. 2003; Bhargava et al. 2006).

O teor lipídico da quinoa varia de 5 a $7 \%$, sendo rico em ácidos graxos essenciais como linoléico e $\alpha$-linolênico, apresentando alta concentração de antioxidantes como $\alpha$-tocoferol e $\gamma$-tocoferol (Ando et al. 2002; Repo-Carrasco et al. 2003; Ng et al. 2007; Abugoch 2009). Uma comparação do perfil de ácidos graxos do óleo do grão com aquele presente no milho e soja revelou quantidades semelhantes para os ácidos graxos linoléico (C18:2), oléico (C18:1) e linolênico (C18:3), correspondendo a aproximadamente $88 \%$ dos ácidos graxos totais da semente.
Embora haja poucos trabalhos sobre o conteúdo de vitaminas no grão, Ruales e Nair (1992) reportaram importantes concentrações

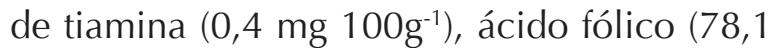
mg $\left.100 \mathrm{~g}^{-1}\right)$, vitamina C $\left(16,4 \mathrm{mg} 100 \mathrm{~g}^{-1}\right)$. RepoCarrasco et al. (2003) também reportaram importantes concentrações de vitaminas A, B e E.

A presença de proteína em quinoa foi investigada por Wright et al. (2002) e Abugoch et al. (2009) que encontraram teores médios variando de $14,2 \%$ a 15,7\%. Para Koziol (1992), Brinegar et al. (1996) e Jancurová et al. (2009a), albuminas e globulinas compõem a maior parte da proteína deste grão (44-47\%) enquanto que as prolaminas estão presentes em baixas concentrações $(0,5-0,7 \%)$.

A quinoa supera os cereais comumente utilizados no Brasil, como milho e trigo, na maioria dos aminoácidos essenciais (Tabela 2) com destaque para a alta concentração de

Tabela 2. Composição de aminoácidos essenciais (mg aminoácido/g proteína) da proteína de quinoa, milho, trigo e arroz

\begin{tabular}{llllll}
\hline \multirow{2}{*}{$\begin{array}{l}\text { Aminoácidos } \\
\text { essenciais }\end{array}$} & \multicolumn{4}{c}{ mg aminoácido/g proteína } \\
\cline { 2 - 5 } & Quinoa $^{1}$ & Milho $^{2}$ & Trigo $^{2}$ & Arroz $^{3}$ & \begin{tabular}{c} 
Padrão $^{\text {FAO/WHO }}$ \\
\hline Fenilalanina + Tirosina
\end{tabular} \\
Histidina & 71,90 & 98,92 & 92,85 & 78,70 & 63 \\
Isoleucina & 36 & 31,83 & 23,41 & 22,70 & 19 \\
Leucina & 42 & 23,35 & 23,81 & 36 & 28 \\
Lisina & 69,30 & 134,78 & 81,48 & 68 & 66 \\
Metionina + Cistina & 44,50 & 25,96 & 25,87 & 22,70 & 58 \\
Treonina & 25,70 & 22,21 & 18,12 & 32 & 25 \\
Triptofano & 43 & 30,36 & 24,67 & 33,30 & 34 \\
Valina & nd.* & n.d & n.d. & n.d. & 11 \\
\hline
\end{tabular}

Fonte: ${ }^{1}$ Borges et al. (2003), ${ }^{2}$ Pires et al. (2006), ${ }^{3}$ Lindeboom (2005), ${ }^{4} \mathrm{FAO} / \mathrm{WHO}$ (1985), *nd.: Não determinado. 
lisina, limitante na maioria dos cereais (Vilche et al. 2003; Abugoch et al. 2008).

Diferenças notáveis no perfil de aminoácidos das farinhas instantâneas de quinoa integral, milho e arroz foram registradas por Ascheri et al. (2002). A quinoa apresentou valores, para a maioria dos aminoácidos, de até 50\% a mais do que as farinhas de milho e arroz. Como comentado anteriormente, é bastante conhecida a limitação da maioria dos cereais quanto ao conteúdo de lisina, e neste estudo, os resultados mostraram que a quinoa possui cerca de 3,6 e 5 vezes mais deste aminoácido do que a quantidade presente no arroz e milho, respectivamente.

Comai et al. (2007) verificaram que a quinoa tem alta concentração de triptofano, geralmente o segundo aminoácido limitante em cereais. Além disso, apresentou índice elevado de triptofano não protéico, mais facilmente absorvido, podendo ter efeito de aumentar a disponibilidade deste aminoácido no cérebro e assim influenciar na síntese do neurotransmissor serotonina.

Os teores dos aminoácidos essenciais lisina, metionina, cisteína e treonina presentes na semente integral, polida e no germe de quinoa foram investigados também por Jacobsen et al. (1997), não sendo verificada diferença nos teores encontrados para nenhum dos produtos analisados. O teor de lisina nestes produtos foi o dobro daquele presente no trigo.

O termo "fator antinutricional" tem sido usado para descrever compostos ou classes de compostos presentes numa extensa variedade de alimentos de origem vegetal, que quando consumidos, reduzem seu valor nutritivo, interferindo em sua digestibilidade, absorção ou utilização de nutrientes e, se ingeridos em altas concentrações, podem acarretar em efeitos danosos à saúde (Santos 2006).

Os fatores antinutricionais presentes na semente de quinoa são saponinas, ácido fítico, taninos e inibidores de tripsina. Estas substâncias encontram-se presentes em maior concentração nas camadas externas do grão (Koziol 1993; Santos 1996). Dentre estes fatores, a saponina é o principal, com teores em genótipos ditos "doces" variando de 0,2 a $0,4 \mathrm{~g} \mathrm{~kg}^{-1}$ de matéria seca e em genótipos "amargos" de 4,7 a 11,3 g kg-1. É, contudo, facilmente removida por métodos úmidos (lavagens em água fria) ou secos (tostagem e abrasão) (Gonzáles et al. 1989; Mastebroek et al. 2000; Comai et al. 2007).

Em escala comercial, utiliza-se o método seco, por descascamento abrasivo para remoção de saponinas. Uma desvantagem deste método é a perda de nutrientes como proteínas, vitaminas e minerais, junto com o farelo. Por esta razão, sugere-se a utilização do método úmido (lavagem) ou sua combinação com o descascamento abrasivo, o que reduz efetivamente os teores de saponina e minimiza a perdas nutricionais (Belton e Taylor 2002; Lindeboom 2005).

De acordo com Reichert et al. (1986) e Chauhan et al. (1992), a etapa de abrasão ou polimento garantem a obtenção de derivados com baixos teores de saponina, uma vez que altas concentrações desta substância encontram-se nas camadas mais externas do grão. 
De acordo com Koziol (1992) e Ruales e Nair (1993), a quantidade de fitato presente na quinoa (0,7-1,2 g\%) encontra-se próxima à do milho $(0,9 \%)$, menor do que no trigo $(0,98$ $1,43 \%$ ) e superior à encontrada no arroz polido $(0,10-0,14 \%)$. O conteúdo de ácido fítico pode ser reduzido sob condições de maceração em água, germinação ou fermentação. A degradação é maior nos processos que favorecem a ativação da fitase, como a fermentação e o cozimento. Em condições naturais nos alimentos, este composto pode formar complexos com minerais (cálcio, ferro, zinco, magnésio e cobre), amido e proteínas, dificultando a digestibilidade e absorção nutricional (Cheryan 1980; Pallauf e Rimbach 1997; Queiroz et al. 1999).

A ação antinutricional de taninos e fitatos baseia-se na capacidade de formar complexos insolúveis com minerais, proteínas e amidos, tornando-os biologicamente indisponíveis para seres humanos em condições fisiológicas normais (Martinez-Valverde et al. 2000; Martinez-Dominguez et al. 2002).

Vários estudos (Mechi et al. 2005; Moura e Canniatti-Brazaca 2006; Ramírez-Cárdenasi et al. 2008) avaliaram o teor de tanino em feijões e verificaram que o grão cozido apresentou diminuição no teor deste composto quando comparado ao produto cru, causada pela ação do processo de cocção. A redução no teor de taninos é muito favorável, pois este fator antinutricional tem a capacidade de reduzir drasticamente a digestibilidade protéica. Na proporção de 5:1, tanino/proteína, toda proteína é precipitada. Estes resultados permitem sugerir que a utilização adequada de etapas de pré-preparo (lavagem e drenagem da água) e preparo (cocção) do grão de quinoa pode favorecer a redução dos taninos presentes, melhorando desta forma, a digestibilidade.

A presença de inibidores de tripsina no trato intestinal inibe a ação da tripsina, que é responsável pela digestão das proteínas, levando a um aumento na produção enzimática pelo pâncreas e à hipertrofia deste órgão. Na nutrição humana tais fatores antinutricionais têm pequena conseqüência, pois são termolábeis e geralmente são destruídos nas condições normais de preparo, doméstico ou industrial dos alimentos (Khattab e Arntfield 2009).

A facilidade relativa com que os inibidores de proteases podem ser destruídos pelo calor permitiu o uso popular de produtos como feijões, uma fonte importante de proteína na dieta humana. Khattab e Arntfield (2009) obtiveram redução total deste componente ao submeter diferentes leguminosas, incluindo feijões e ervilhas à lavagem e maceração em água por período de 18 a 22 horas a tratamentos térmicos como fervura, torrefação, microondas e autoclavagem. Esse fato demonstra que a inativação deste antinutriente na quinoa pode ser obtida por técnicas de preparo geralmente empregadas no preparo doméstico de alimentos.

Improta e Kellens (2001) verificaram que o uso de quinoa integral na alimentação de frangos de corte interferiu negativamente no crescimento, ganho de peso e sobrevivência das aves, sendo o posto observado com dietas contendo quinoa lavada ou polida. Para os autores, estes resultados demonstraram a eficácia das etapas de lavagem ou polimento na eliminação de riscos decorrentes do consumo deste grão. 
Apesar da presença dos fatores antinutricionais no grão de quinoa, estas substâncias podem ser inativadas ou reduzidas a níveis seguros à saúde quando são utilizadas técnicas adequadas de processamento industrial e/ou doméstico no preparo do grão.

\section{PREPARO E UTILIZAÇÃO}

A industrialização da quinoa para utilização direta do grão ou por meio de sua utilização como matéria-prima na obtenção de inúmeros produtos alimentícios, ocorre por meio úmido (a), realizado com água a temperatura de 60 ${ }^{\circ} \mathrm{C}$, período de repouso, seguido de agitação brusca, drenagem e secagem; por meio seco (b), pelo uso de um sistema mecânico abrasivo, em combinação com paletas ou hastes giratórias, para a separação do episperma e demais estruturas; ou ainda pela combinação de ambos (c) promovendo a obtenção de derivados de maior valor agregado (Mendonza 1993).

Comercialmente, este grão pode ser encontrado nas formas integral ou polido, como farinhas, flocos ou snacks expandidos. Pode ser consumido cozido, de modo similar ao arroz; em combinação com outros ingredientes em diferentes preparações alimentícias; em sopas, molhos; cereais matinais, dentre outros. A farinha pode ser utilizada na elaboração de mingaus, pudins, produtos de panificação (pães, bolos, biscoitos) e massas (macarrão) (Lindeboom 2005; Bhargava et al. 2006; Spehar 2006; Rocha 2008; Jancurová et al. 2009b).

A quinoa é uma matéria-prima com possibilidades de transformação e utilização em diferentes produtos, como o extrato líquido vegetal "leite vegetal", e farinhas instantâneas
(Ascheri et al. 2002; Jacobsen et al. 2003). Vários estudos têm sido realizados para investigar a viabilidade de incorporação deste grão em alimentos, objetivando, sobretudo, a melhoria da qualidade nutricional. Lorenz e Coulter (1991) e Lorenz et al. (1995) avaliaram a influência da mistura de farinhas de quinoa e trigo em pães e bolos e verificaram que os melhores resultados foram obtidos com substituição máxima de $10 \%$ de farinha de trigo pela farinha de quinoa.

As propriedades nutricionais, sensoriais e físicas de extrusados expandidos a base de gritz de milho e quinoa foram estudadas por Coulter e Lorenz (1991) e Lorenz et al. (1995). Os resultados permitiram concluir que a adição de quinoa favoreceu ao aumento na densidade, com conseqüente diminuição da capacidade de expansão. Os produtos foram considerados moderadamente aceitos pela avaliação sensorial.

Os efeitos da temperatura $\left(130-170{ }^{\circ} \mathrm{C}\right)$, da rotação de rosca (250-500 rpm) e da umidade (16-24\%) sobre as características físicoquímicas de extrusados de quinoa foram investigados por Dogan e Karwe (2003). Os melhores resultados (máxima expansão, mínima densidade, alto grau de gelatinização; baixo índice de solubilidade em água) foram obtidos pela combinação de baixo teor de umidade $(16 \%)$ e temperatura $\left(130{ }^{\circ} \mathrm{C}\right)$ e velocidade média para rotação de rosca (375 rpm), demonstrando que farinha deste grão pode ser usada na elaboração de produtos alimentícios, tipo snack, por meio de extrusão termoplástica.

As características químicas e de qualidade 
protéica de um mingau desidratado à base de quinoa foram avaliadas por Ruales et al. (2002). A análise química revelou um produto com boas características nutricionais conforme os teores de proteína (16\%), vitamina E (19 $\left.\mathrm{mg} \mathrm{kg}^{-1}\right)$, tiamina $\left(0,7 \mathrm{mg} \mathrm{kg}^{-1}\right)$, ferro (70 $\mathrm{mg} \mathrm{kg}^{-1}$ ), zinco (48 $\mathrm{mg} \mathrm{kg}^{-1}$ ) e magnésio $\left(1,8 \mathrm{~g} \mathrm{~kg}^{-1}\right)$. Valores de utilização líquida da proteína e digestibilidade verdadeira de $68 \%$ e $95 \%$, respectivamente, foram obtidos em experimento biológico com ratos. De acordo com Berti et al. (2005), a mistura de farinhas de quinoa com a de cereais é uma alternativa viável para melhorar a qualidade nutricional e funcional de seus produtos finais.

Farinha de quinoa foi adicionada à formulação de chocolate meio amargo nas proporções de $12 \%, 16 \%$ e $20 \%$, com o objetivo de aumentar o percentual de proteína. Os resultados demonstraram que a adição de quinoa reduziu a quantidade de polifenóis e aumentou os teores de vitamina E, proteína e todos os aminoácidos essenciais, além de apresentar boa aceitabilidade no teste de análise sensorial (mínima de 70\%) e aprovação (92\%) entre os avaliadores (Schumacher 2008).

Os parâmetros qualidade de macarrão à base de milho e quinoa foram estudados por Caperuto et al. (2001). Os resultados foram favoráveis ao uso da mistura destas farinhas, considerando os parâmetros qualidade de cozimento (perda de sólidos, aumento de volume, aumento de peso) e textura (adesividade e elasticidade). A avaliação demonstrou boa aceitabilidade pelos provadores.

Borges et al. (2003) estudaram a qualidade de cozimento de macarrões pré-cozidos a base de farinha integral de quinoa e arroz, verificando baixos valores para os parâmetros aumento de peso, volume, rendimento e densidade, e elevados teores de sólidos solúveis na água de cozimento.

\section{CONCLUSÕES}

Pelas características nutricionais do grão de quinoa, superiores à maioria dos cereais comumente consumidos no Brasil (milho, trigo e arroz), torna-se interessante que sua produção agrícola e seu consumo sejam estimulados, incluindo sua inserção como matéria-prima na indústria de alimentos, uma vez que há um mercado em expansão caracterizado pela procura por alimentos mais nutritivos. Por sua composição físico-química e valor nutricional, destaca-se como matéria prima importante na diversificação de produtos alimentícios para portadores de doença celíaca. Embora o grão apresente alguns fatores antinutricionais, estes são facilmente removidos durante o processamento industrial ou pelo emprego de técnicas adequadas de manipulação e preparo doméstico de alimentos, geralmente aplicadas para a maioria dos grãos utilizados na alimentação humana.

\section{AGRADECIMENTOS}

À Fundação de Amparo à Pesquisa do Estado da Bahia (FAPESB)/Conselho Nacional de Desenvolvimento Científico e Tecnológico (CNPq) pela bolsa concedida e ao Departamento de Engenharia de Alimentos da Universidade Estadual do Sudoeste da Bahia pelo apoio na realização deste trabalho. 


\section{REFERÊNCIAS}

Abugoch James, L.E. 2009. Quinoa (Chenopodium quinoa Willd.) composition, chemistry, nutritional, and functional properties. Advances in Food and Nutrition Research 58 (Cap.1): 1-31.

Abugoch, L., Castro, E., Tapia, C., Anõn, M.C., Gajardo, P. e Villarroel, A. 2009. Stability of quinoa flour proteins (Chenopodium quinoa Willd.) during storage. International Journal of Food Science and Technology 44(10): 2013-2020.

Abugoch, L.E., Romero, N., Tapia, C.R., Silva, J. e Rivera, M. 2008. Study of Some Physicochemical and Functional Properties of Quinoa (Chenopodium quinoa Willd) Protein Isolates. Journal of Agricultural and Food chemistry 56(12): 4745-4750.

Almeida, P.L., Gandolfi, L., Modelli, I.C., Martins, R.C., Almeida, R.C. e Pratesi, R. 2008. Prevalence of celiac disease among first degree relatives of Brazilian celiac patients. Arquivos de Gastroenterologia 45(1): 69-72.

Ando, H., Chen, Y, Tang, H., Shimizu, M., Watanabe, K. e Mitsunaga, T. 2002. Food components in fractions of quinoa seed. Food Science and Technology Research 8(1): 80-84.

Ascheri, J., Nascimento, R. e Spehar, C. 2002. Composição química comparativa de farinha instantânea de quinoa, arroz e milho. Rio de Janeiro: Embrapa, Comunicado Técnico, p.1-4, out.

Belton, P.S. e Taylor, J.R.N. 2002. Pseudocereals and Less Common Cereals: Grain Properties and Utilization Potential. Berlin: Springer Verlag. 269p.

Berti, C., Riso, P., Brusamolino, A. e Porrini, M. 2005. Effect on appetite control of minor cereal and pseudocereal products. British Journal of Nutrition 94(5): 850-858.

Bhargava, A., Shukla, S. e Ohri, D. 2006. Chenopodium quinoa-An Indian perspective. Industrial Crops and Products 23(1): 73-87.

Borges, J., Ascheri, J., Ascheri, D., Nascimento, R. e Freitas, A. 2003. Propriedades de cozimento e caracterização físicoquímica de macarrão pré-cozido à base de farinha integral de quinoa (Chenopodium quinoa, Willd) e de farinha de arroz (Oryza sativa, L) polido por extrusão termoplástica. Boletim CEPPA 21(2): 303-322.

Brady, K., Ho, C., Rosen, R., Sang, S. e Karwe, M. 2007. Effects of processing on the nutraceutical profile of quinoa. Food Chemistry 100(3): 1209-1216.

Brinegar, C., Sine, B. e Nwokocha, L. 1996. High-Cysteine $2 \mathrm{~S}$ seed storage proteins from quinoa (Chenopodium quinoa). Journal of Agricultural and Food Chemistry 44(7): 1621-1623. 
Caperuto, L., Amaya-Farfan, J. e Camargo,

C. 2001. Performance of quinoa (Chenopodium quinoa Willd) flour in the manufacture of gluten-free spaghetti. Journal of the Science of Food and Agriculture 81(1): 95-101.

Castro, L.I.A., Vila real, C.M., Pires, I.S.C., Pires, C.V., Pinto, N.A.V.D., Miranda, L.S., Rosa, B.C. e Dias, P.A. 2007. Quinoa (Chenopodium quinoa willd): digestibilidade in vitro, desenvolvimento e análise sensorial de preparações destinadas a pacientes celíacos. Alimentos e Nutrição, Araraquara 18(4): 413-419.

Chauhan, G., Eskin, N. e Tkachuk, R. 1992. Nutrients and anti-nutrients in quinoa seed. Cereal Chemistry 69(I): 85-88.

Cheryan, M. 1980. Phytic acid interactions in food systems. Critical Reviews and Food Science and Nutrition 13(4): 297-335.

Comai, S., Bertazzo, A., Bailoni, L., Zancato, M., Costa, C.V.L. e Allegri, G. 2007. The content of proteic and nonproteic (free and protein-bound) tryptophan in quinoa and cereal flours. Food Chemistry 100(4): 1350-1355.

Coulter, L. e Lorenz, K. 1991. Extruded corn grits-quinoa blends. I. Proximate composition, nutritional properties and sensory evaluation. Journal of Food Processing and Preservation 15(4): 231-242.
Dini, I.; Tenore, G.C.; Trimarco, E. e Dini, A. 2006. Two novel betaine derivatives from Kancolla seeds (Chenopodiaceae). Food Chemistry, 98(2): 209213.

Dogan, H. e Karwe, M. 2003. Physicochemical properties of quinoa extrudates. Food Science and Technology International 9(2): 101-114.

Estudio de Quinua. 2003. http://infoagro.net/ shared/docs/a5/cproandinos5.PDF [12 de junho 2010].

Food and Agriculture Organization/World Health Organization - FAO/WHO. 1985. Necessidades de energia $y$ de proteínas. Ginebra: OMS. 220p. (Informe de una réunion consultiva conjunta FAO/OMS/UNU de expertos).

Gely, M.C.; Santalla, E. 2007. Moisture diffusivity in quinoa (Chenopodium quinoa Willd.) seeds: effect of air temperature and initial moisture content of seeds. Journal of Food Engineering, 78(3): 1029-1033.

Gonzáles, J., Roldman, A., Gallardo, M., Escudero, T. e Prado, F. 1989. Quantitative determination of chemical compounds with nutritional value from Inca crops: Chenopodium quinoa (quinoa). Plant Foods Human Nutrition 39(4): 331-337.

Hunt, J., Johnson, L. e Juliano, B. 2002. Bioavailability of zinc from cooked 
Philippine milled, undermilled, and brown rice, as assessed in rats by using growth, bone zinc, and zinc- 65 retention. Journal of Agriculture and Food Chemistry 50(18): 5229-5235.

Improta, F. e Kellens, R. 2001. Comparison of raw, washed and polished quinoa (Chenopodium quinoa Willd.) to wheat, sorghum or maize based diets on growth and survival of broiler chicks. Livestock Research for Rural Development 13(1). http://www.Irrd. org/lrrd13/1/cont131.htm. [12 de junho 2010].

Jacobsen, S., Mujica, A. e Ortiz, R. 2003. La Importancia de los Cultivos Andinos. Fermentum Mérida 13(36): 14-24.

Jacobsen, E., Skadhauge, B. e Jacobsen, S. 1997. Effect of dietary inclusion of quinoa on broiler growth performance. Animal Feed Science and Technology 65(1-4): 5-14.

Jancurová, M., Minarovičová, L. e Dandár, A. 2009a. Quinoa: a review. Czech Journal of Food Sciences 27(2): 7179.

Jancurová, M., Minarovičová, L. e Dandár, A. 2009b. Rheological properties of doughs with buckwheat and quinoa additives. Chemical Papers 63(6): 738-741.

Khattab, R.Y. e Arntfield, S.D. 2009. Nutritional quality of legume seeds as affected by some physical treatments
2. Antinutritional factors. LWT-Food Science and Technology 42(6): 11131118.

Konish, Y., Hirano, S., Tsuboi, H. e Wada, M. 2004. Distribuition of minerals in quinoa (Chenopodium quinoa Willd.) seeds. Bioscience Biotechnology Biochemistry 68(1): 231-234.

Koziol, M. 1992. Chemical composition and nutritional evaluation of quinoa (Chenopodium quinoa Willd.). Journal of Food Composition and Analysis 5(1): 35-68.

Koziol, M. 1993. In.: Janick, J., Simon, J. (Eds.). Quinoa: A Potential New Oil Crop. New Crops. Wiley, New York, p.328336.

Lindeboom, N. 2005. Studies on the characterization, biosynthesis and isolation of starch and protein from quinoa (Chenopodium quinoa Willd.). Tese de Doutorado, University of Saskatchewan, Saskatoon.

Lorenz, K. e Coulter, L. 1991. Quinoa flour in baked products. Plant Foods for Human Nutrition 41(3): 213-224.

Lorenz, K., Coulter, L. e Johnson, D. 1995. Functional and sensory characteristics of quinoa in foods. Developments in Food Science 37(1): 1031-1041.

Martinez-Valverde, I., Periago, M. e Ros, G. 2000. Significado nutricional de los compuestos fenólicos de la 
dieta. Archivos Latinoamericanos de Nutrición 50(1): 5-18.

\section{Martinez-Dominguez, B., Ibañez, M. e Rincón,} F. 2002. Acido fítico: aspectos nutricionales e implicaciones analíticas. Archivos Latinoamericanos de Nutrición 52(3): 219-231.

Mastebroek, H., Limburg, H., Gilles, T. e Marvin, H. 2000. Occurrence of sapogenins in leaves and seeds of quinoa (Chenopodium quinoa Willd.). Journal of the Science of Food and Agriculture 80(1): 152-156.

Mearin, M.L., Ivarsson, A. e Dickey, W. 2005. Coeliac disease: is it time for mass screening? Best Practice \& Research Clinical Gastroenterology 19 (3): 441-52.

Mechi, R., Caniatti-Brazaca, S. e Arthur, V. 2005. Avaliação química, nutricional e fatores antinutricionais do feijão preto (Phaseolus vulgaris I.) irradiado. Ciência e Tecnologia de Alimentos 25(1): 109-114.

Mendoza, G. 1993. Alternativas de producción y consumo de quinua en Colombia. Instituto Colombiano de Bienestar Familiar, ICBF. 185 p.

Moura, N. e Canniatti-Brazaca, S. 2006. Avaliação da disponibilidade de ferro de feijão comum (Phaseolus vulgaris L.) em comparação com carne bovina. Ciência e Tecnologia de Alimentos 26(2): 270-276.
Ng, S., Anderson, A., Coker, J. e Ondrus, M. 2007. Characterization of lipid oxidation products in quinoa (Chenopodium quinoa). Food Chemistry 101(1): 185-192.

Nsimba, R., Kikuzaki, H. e Konishi, Y. 2008. Antioxidant activity of various extracts and fractions of Chenopodium quinoa and Amaranthus spp. seeds. Food Chemistry 106(2): 760-766.

Núcleo de Estudos e Pesquisa em Alimentos - NEPA. 2006. Tabela brasileira de composição de alimento (versão 2). Campinas: NEPA-UNICAMP, $114 \mathrm{p}$.

Ogungbenle, H. 2003. Nutritional evaluation and functional properties of quinoa (Chenopodium quinoa) flour. International Journal of Food Sciences and Nutrition 54(2): 153-158.

Pallauf, J. e Rimbach, G. 1997. Nutritional significance of phytic acid and phytate. Archives of Animal Nutrition 50(4): 301-310.

Pires, C., Oliveira, M., Rosa, J. e Costa, N. 2006. Qualidade nutricional e escore químico de aminoácidos de diferentes fontes protéicas. Ciência e Tecnologia de Alimentos 26(1): 179-187.

Prego, I., Maldonado, S. e Otegui, M. 1998. Seed structure and localization of reserves in Chenopodium quinoa. Annals of Botany 82(4): 481-488. 
Queiroz, K., Helbig, E., Reis, S., Carraro, F. e Oliveira, A. 1999. O processamento doméstico de feijão-comum ocasiona uma redução nos fatores antinutricionais fitatos e taninos e no fator de flatulência estaquiose. Livro de Resumos do $5^{\circ}$ Congresso Nacional da Sociedade Brasileira de Alimentação e Nutrição 1999, São Paulo. São Paulo: Sociedade Brasileira de Alimentação e Nutrição, p.174.

Ramirez-Cárdenasi, L.; Leonel, A.J. e Costa, N.M.B. 2008. Efeito do processamento doméstico sobre o teor de nutrientes e de fatores antinutricionais de diferentes cultivares de feijão comum. Ciência e Tecnologia de Alimentos 28(1): 200-213

Reichert, R., Tatarynovich, J. e Tyler, T. 1986. Abrasive dehulling of quinoa (Chenopodium quinoa): effect on saponin content as determined by an adapted hemolytic assay. Cereal Chemists 63(6): 471-475.

Repo-Carrasco, R., Espinoza, C. e Jacobsen, S. 2003. Nutritional value and use of the Andean crops quinoa (Chenopodium quinoa) and kañiwa (Chenopodium pallidicaule). Food Reviews International 19(1-2): 179-189.

Rocha, J. 2008. Seleção de genótipos de quinoa com características agronômicas e estabilidade de rendimento no planalto central. Tese de Mestrado: Universidade de Brasília/Faculdade de Agronomia e Medicina Veterinária, Brasília.
Rodrigo, L. 2006. Celiac disease. World Journal of Gastroenterology 12(41): 6585-6593.

Rojas, W., Soto, J. e Carrasco, E. 2004. Estudio de los impactos sociales, ambientales y económicos de la promoción de la quinua en Bolivia. Bolivia: Fundación PROINPA.

Ruales, J., Grijalva, Y., Jaramillo, P. e Nair, B. 2002. The nutritional quality of an infant food from quinoa and its effect on the plasma level of insulin-like growth factor-I (IGF-I) in undernourished children. International Journal of Food Sciences and Nutrition 53(2): 143-154.

Ruales, J. e Nair, B. 1992. Nutritional quality of the protein in quinoa (Chenopodium quinoa Willd) seeds. Plant Foods for Human Nutrition 42(1): 1-11.

Ruales, J. e Nair, B. 1993. Content of fat, vitamins and minerals in quinoa (Chenopodium quinoa Willd.) seeds. Food Chemistry 48(2): 131-136.

Santos, R. 1996. Estudos iniciais para o cultivo de quinoa (Chenopodium quinoa, Willd) nos Cerrados. Tese de Mestrado, Universidade de Brasília, Brasília.

Santos, M.A.T. 2006. Efeito do cozimento sobre alguns fatores antinutricionais em folhas de brócoli, couve- flor e couve. Ciência e Agrotecnologia 30(2): 294-301. 
Schumacher, A. 2008. Desenvolvimento de um chocolate meio amargo com maior percentual de proteína. Tese de Mestrado, UFRGS, Porto Alegre.

Spehar, C. 2002. Utilização da quinoa como alternativa para diversificar alimentos. In: SIMPÓSIO SOBRE INGREDIENTES NA ALIMENTAÇÃO ANIMAL, 2., 2002, Uberlândia. Anais... Uberlândia, MG: Colégio Brasileiro de Nutrição Animal: UFU, p. 4958.

Spehar, C. 2006. Adaptação da quinoa (Chenopodium quinoa Willd.) para incrementar a diversidade agrícola e alimentar no Brasil. Cadernos de Ciência \& Tecnologia 23(1): 41-62.

Spehar, C., Santos, R. 2002. Quinoa BRS Piabiru: alternativa para diversificar os sistemas de produção de grãos. Pesquisa Agropecuária Brasileira 37(6): 889-893.
Spehar, C., Santos, R. e Nasser, L. 2003. Diferenças entre Chenopodium quinoa e a planta daninha Chenopodium album. Planta Daninha 21(3): 487-491.

Tapia, M. 1997. Cultivos andinos subexplotados y su aporte a la alimentación. Santiago, Chile: Oficina Regional de la FAO para la América Latina y Caribe, 217 p.

Vilche, C., Gely, M. e Santalla, E. 2003. Physical properties of quinoa seeds. Biosystems Engineering 86(1): 59-65.

Wright, K., Pike, O., Fairbanks, D. e Huber, C. 2002. Composition of Atriplex hortensis, sweet and bitter Chenopodium quinoa seeds. Journal of Food Science 67(4): 1383-1385 